\title{
Redescription of the archosaur Parringtonia gracilis from the Middle Triassic Manda beds of Tanzania, and the antiquity of Erpetosuchidae - CORRIGENDUM
}

\author{
STERLING J. NESBITT \& RICHARD J. BUTLER
}

doi:10.1017/S0016756812000362, Published by Cambridge University Press, 30 August 2012.

The lengths of scale bars indicated on figures 1, 2, 3, 5, and 6 in the above publication (Nesbitt \& Butler, 2012) are incorrectly defined in the figure captions. They should read:

Figure 1. Scales $=5 \mathrm{~mm}$.

Figure 2. Scale in $A$ and $B=10 \mathrm{~mm}, C, G-H=5 \mathrm{~mm}, D-F=2 \mathrm{~mm}$.

Figure 3. Scale $=5 \mathrm{~mm}$.

Figure 5. Scale $=5 \mathrm{~mm}$.

Figure 6. Scale $=5 \mathrm{~mm}$.

\section{Reference}

Nesbitt, S. J. \& ButleR, R. J. 2012. Redescription of the archosaur Parringtonia gracilis from the Middle Triassic Manda beds of Tanzania, and the antiquity of Erpetosuchidae. Geological Magazine. Published online 30 August 2012. doi:10.1017/S0016756812000362. 